\title{
UMA AVENTURA NO MUNDO DAS DIVERSAS LINGUAGENS: \\ EDUCAÇÃO INFANTIL E A LINGUAGEM ESCRITA
}

Fabiana Teixeira da Rosa

Mara Siluandra Rodrigues Klosinski

\section{Introdução}

Nosso primeiro contato com a Creche Almirante Lucas Alexandre Boiteux aconteceu na $7^{\mathrm{a}}$ fase, onde conhecemos os 13 grupos de crianças da Instituição, a equipe pedagógica e o espaço físico. Após a apresentação, seguimos para a escolha do grupo de crianças de acordo com as afinidades de cada dupla de estagiárias. Escolhemos o grupo G5A, formado por crianças de 3 a 4 anos, sendo 7 meninos e 11 meninas, e coordenado pela professora Andréia e pela professora auxiliar Mara. No decorrer da $8^{a}$ fase houve a admissão de outra professora auxiliar, Elizane, devido a inclusão de uma criança com necessidades especiais.

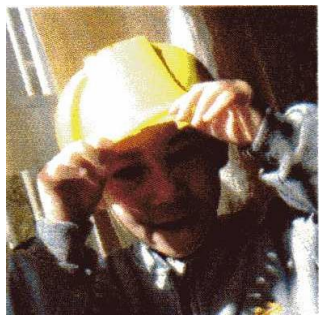

Israel

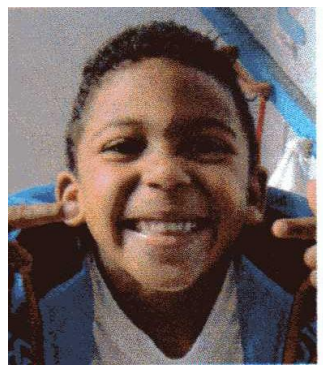

Jean

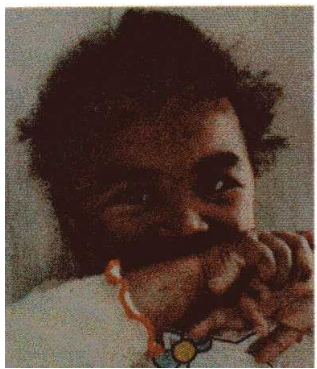

Gabrielly

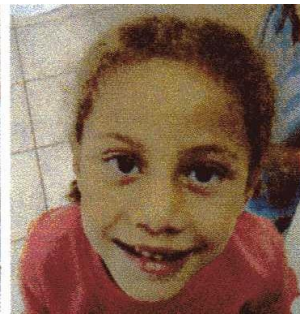

Luiza

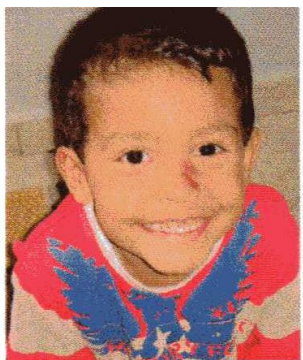

Renato

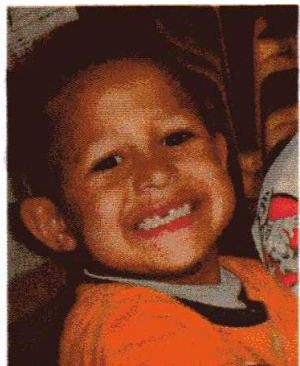

Júnior

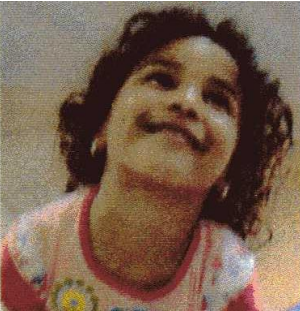

Iasmin

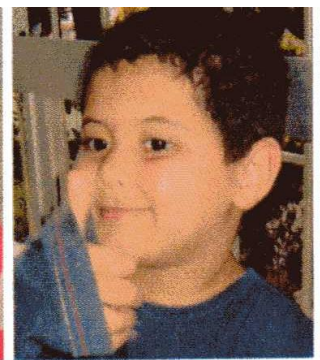

Nicolas

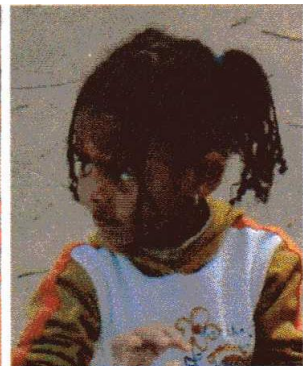

Hágata

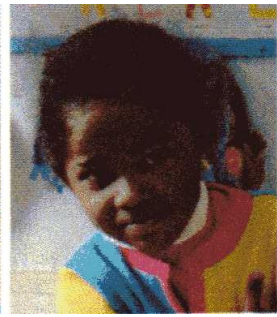

Letícia

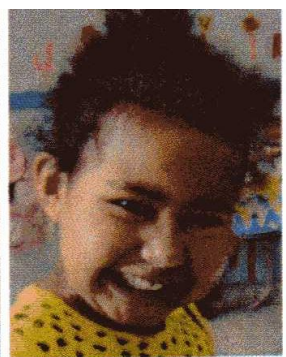

Roberta

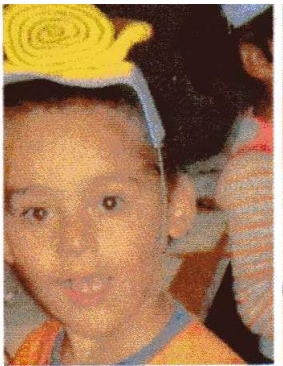

Guilherme

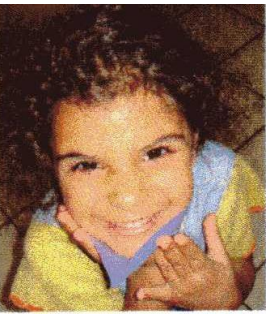

Maria Júlia

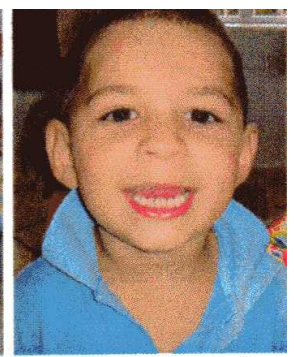

Luciano

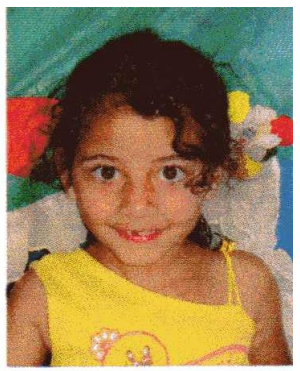

Caillane 


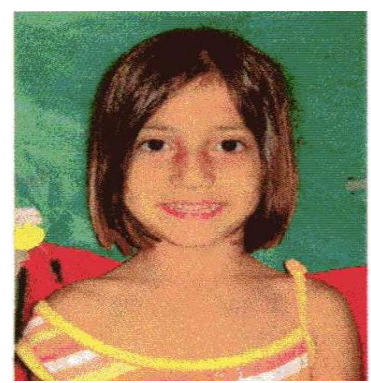

Lara

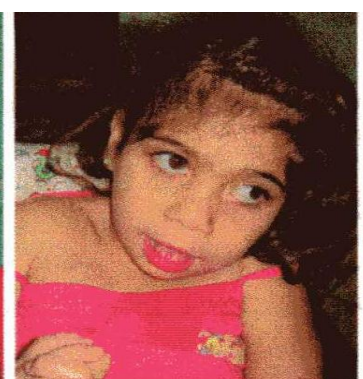

Daniele

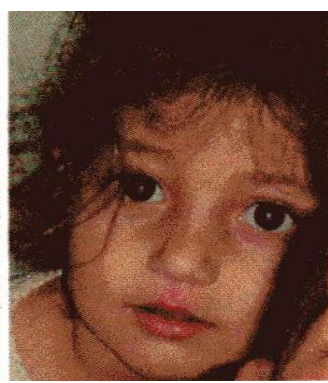

Luana

Desde o começo fomos bem recebidas, tanto pelas crianças quanto pelas professoras que sempre tiveram a preocupação de nos integrar no grupo. As crianças deste grupo sempre foram muito receptivas, criando assim uma relação afetiva, desde a nossa chegada na Instituição. Aos poucos, fomos conquistando a confiança de todos, sendo solicitada em vários momentos nossa atenção e nossa ajuda. A nossa presença se fez como parte do cotidiano do grupo.

Este grupo de crianças apresenta as seguintes características: é originário de famílias com baixo poder aquisitivo; a maior parte das mães é adolescente, ficando as crianças muitas vezes sob responsabilidade dos avós; permanece na sua maioria por período integral na Instituição, ou seja, quase 12 horas.

A rotina das crianças deste grupo ocorre da seguinte forma: por volta das $7 \mathrm{~h}$ as crianças começam a chegar, tomam o café da manha entre $8 \mathrm{~h}$ e $8: 30 \mathrm{~h}$ e em seguida realizam atividades “dirigidas", normalmente depois são encaminhadas ao parque. Às $11 \mathrm{~h}$ as crianças almoçam no refeitório e retomam para a sala onde acontece o momento do sono. O lanche vespertino ocorre por volta de 13:30h, nas próximas horas os trabalhos são divididos entre momentos livres e/ou dirigidos na sala das crianças e o brincar no parque. A janta acontece às $16 \mathrm{~h}$, depois as crianças voltam para a sala e preparam-se para a saída, realizando a higiene e a troca de roupas quando necessário. Os Pais começam a buscar as crianças a partir das $17 \mathrm{hs}$.

Percebemos que a rotina da Creche Almirante Lucas Boiteux é flexível, sendo organizada de acordo com as particularidades de cada grupo de crianças. Por exemplo, no momento do lanche vimos que as educadoras têm a possibilidade de escolher lanchar na sala ou no refeitório, conforme as necessidades da sua turma. Outro momento em que essa flexibilidade pôde ser observada foi na "hora do soninho", onde geralmente as professoras permitem que as crianças acordem "ao seu tempo", ou seja, não exigem que todas levantem no mesmo horário (enquanto umas acordam e lancham, outras ainda permanecem dormindo).

Quando chegamos no campo de estágio, as crianças do nosso grupo já estavam lanchando no espaço do refeitório. Havia ainda três crianças dormindo na sala e estas lancharam somente após acordarem, acompanhadas sempre pela professora auxiliar, enquanto a professora do 
grupo com a nossa ajuda servia o lanche ao restante do grupo no refeitório (REGISTRO, 21/08/2006).

Falar do trabalho cotidiano nas Instituições de Educação Infantil é falar de tempos, espaços e atividades, por meio dos quais se estruturam e se desenvolvem interações protagonizadas por adultos e crianças. É falar sobre modos de organizar o dia-a-dia: o que, quando e onde fazer. Enfim, falar do trabalho cotidiano é falar de rotina. Segundo os Cadernos da Educação Infantil da Secretaria de Educação de Blumenau:

O dia-a-dia é marcado por diferentes momentos que se repetem, no contínuo processo de educar e cuidar as crianças em grupo. Repetir não significa "mesmice" ou rigidez e, então, momentos como a chegada da criança, a hora da alimentação, a hora do descanso entre outros, que acontecem todo dia, podem se tornar prazerosos e flexíveis ou dolorosos e mecânicos, conforme planejados e viabilizados; dependem das atitudes dos adultos que estão à frente, coordenando esses processos (BLUMENAU, SECRETARIA MUNICIPAL DE EDUCAÇÃO, 2002, p. 35).

De acordo com a abordagem do projeto político pedagógico da Instituição, o contexto educacional infantil não implica simplesmente, enfocar a multiplicidade de objetos que distraem as crianças e ocupam seu tempo. A organização do ambiente físico deve estar a favor da estruturação do cotidiano, do cuidado e da educação da criança de $\mathrm{O}$ a 6 anos, de modo que tal não deve ser pensado sob a ótica dos padrões de beleza e de comodidade do usuário, mas sim, tendo por base o desenvolvimento integral da criança de acordo com a sua faixa etária. Para este tema, o Referencial Curricular Nacional para Educação Infantil, cita que:

A disposição dos materiais e utensílios pedagógicos é fator que interfere diretamente nas possibilidades do "fazer sozinho", devendo ser, também, alvo de reflexão e planejamento do professor e da instituição. Uma sugestão é que os materiais pedagógicos, brinquedos e outros objetos estejam à disposição, organizados de tal forma que possam ser encontrados sem a necessidade de interferência do adulto, dispostos em altura ao alcance das crianças, em caixas ou prateleiras, etc, sobretudo em ambientes especialmente organizados para brincar, como casinhas, garagem, circo, feira, etc (BRASIL, 1998, pág. 39).

Assim, tendo em vista os eixos norteadores da educação infantil (jogos, interações e linguagens), elaboramos na 7 fase o projeto de estágio coletivo na qual apresentou como foco a Autonomia e a Interação no Contexto da Creche Almirante Lucas Alexandre Boiteux. Foi a partir das reflexões que pensamos a construção de um projeto de estágio que viesse ao encontro da proposta já em execução na Instituição ${ }^{1}$. Além da contribuição do tema para melhorar a qualidade

\footnotetext{
${ }^{1}$ Conforme apresenta no Projeto Político Pedagógica da Instituição, como um dos princípios norteadores da prática pedagógica da Creche, destacamos: Autonomia - conceber uma educação em direção a autonomia significa considerar as crianças como sujeitos de vontade, capazes e competentes para construir conhecimentos e dentro de suas possibilidades interferir no meio em que atuam. Interação - propiciar a interação quer dizer, portanto, considerar que as diferentes formas de sentir, expressar e comunicar a realidade pelas crianças resulta em respostas diversas que são trocadas entre elas e que garantem parte significativa de suas aprendizagens.
} 
das práticas educativas da Creche, o assunto é relevante para as próprias crianças, pois segundo o Referencial Curricular Nacional para a Educação Infantil, a autonomia é nessa faixa etária mais do que um objetivo a ser alcançado pelas crianças, um princípio das ações educativas:

Conceber uma educação em direção à autonomia significa considerar as crianças como seres com vontade própria, capazes e competentes para construir conhecimentos, e, dentro de suas possibilidades, interferir no meio em que vivem. Exercitando o autogoverno em questões situadas no plano das ações concretas, poderão gradualmente fazê-lo no plano das idéias e dos valores (BRASIL, 1998, p.14).

A partir das vivências oportunizadas pelas observações e coordenações realizadas no decorrer de todo o estágio estabelecemos relações com as educadoras e com as crianças e conhecemos os projetos em andamento no grupo em questão. No período do estágio de observações ocorridos na $8^{\mathrm{a}}$ fase, a professora do grupo encontrava-se no processo de sistematização dos projetos de trabalho que estavam em andamento com as crianças. Um dos projetos refere-se a criação de um livro de receitas do grupo G5A, onde os pais podem dar idéias de receitas e colaborar com os ingredientes para a realização das mesmas pelas próprias crianças na sala. Como produto final a professora propôs que algumas receitas fossem apresentadas aos pais no final do ano, além da entrega de um livro formado pelas receitas que foram desenvolvidas durante este ano pelas criança.

Outro projeto que já estava em desenvolvimento pela professora diz respeito a associação do nome das crianças com um símbolo, já escolhido por elas no início do ano. A professora procura desenvolver este projeto realizando atividades em um caderno, onde articula o símbolo da criança com a letra inicial do seu nome, além de outras atividades relacionadas com o símbolo, conforme consta em nosso registro de observação do dia em que participamos da reunião de planejamento pedagógico com a professora do grupo, professoras auxiliares e a supervisora da creche:

Nesta reunião sistematizaram o projeto que estão desenvolvendo neste momento com o grupo,
sendo o tema Símbolos. Neste projeto, a partir do interesse das crianças pela linguagem
escrita, cada criança tem um símbolo para reconhecer seu nome. Trabalha-se em uma
semana este símbolo associando-o a letra inicial do nome da criança e também ao próprio
nome. O objetivo deste projeto é o incentivo da escrita por meio dos símbolos (REGISTRO,
23/08/2007).

Deste modo, o projeto de trabalho desenvolvido na $8^{\text {a }}$ fase buscou dar continuidade ao projeto dos Símbolos, com a intenção de enfatizar a organização do espaço, de oportunizar outras possibilidades de interações e linguagens, de diversificar as brincadeiras e de ampliar o repertório cultural das crianças; além de integrar o tema do nosso projeto de estágio elaborado na $7^{\mathrm{a}}$ fase e o projeto político-pedagógico da creche, apresentando como tema: "Nomes e Símbolos: Uma Aventura no Mundo dos Bichos". Procuramos resgatar os símbolos já trabalhados pela professora e acrescentamos outros de acordo com o interesse das crianças

Foi a partir das observações, dos momentos de coordenações com este grupo, das discussões com as orientadoras e, principalmente, dos nossos questionamentos do período de estágio, que 
chegamos ao tema que abordaremos no decorrer deste relatório, partindo da perspectiva históricocultural. Discutiremos sobre a relação entre educação infantil e as diversas linguagens, tendo como ênfase à linguagem escrita. Trabalhar com as diversas linguagens na educação infantil é importante para a formação da identidade do sujeito e sua personalidade, além da interação com o outro, da construção de muitos conhecimentos e do desenvolvimento do pensamento. A linguagem é carregada de interações sociais e não é nada neutra; é atividade característica do conhecimento do mundo pela criança.

No momento seguinte, faremos uma reflexão acerca de como trabalhar a linguagem escrita na educação infantil. O que se sugere como princípio é que ao entrar no universo da escrita, operandose com signos e significados, se tenha o intuito de construir bases para que as crianças possam desenvolver-se e participar criticamente da cultura escrita. O desafio não é o de ensinar simplesmente as letras, mas experimentar de diferentes formas os modos de pensar típicos do escrito.

\section{O Papel da Linguagem no Desenvolvimento da Criança}

O desenvolvimento das diversas linguagens é essencial para as crianças ampliarem suas possibilidades de inserção e de participação nas várias práticas sociais. $\mathrm{O}$ trabalho com a linguagem se constitui um dos eixos básicos na educação infantil, devida sua importância na formação do sujeito, na interação com as outras pessoas, na orientação das ações das crianças, na construção de muitos conhecimentos e no desenvolvimento do pensamento.

A relação da criança com a cultura - muito antes do domínio da fala — ocorre por meio de leituras diferentes e a manifestação de expressões pelas crianças, igualmente envolve distintas linguagens. E, mais que aprender as palavras, é preciso apropriar-se dos significados culturais, e com eles, os modos pelos quais as pessoas do seu meio sociocultural entendem, interpretam e representam a realidade.

Em uma das atividades do período de coordenações do estágio, conversamos sobre a "casinha" da sala com as crianças ao trabalhar o símbolo de uma das crianças (Guilherme) que era o Caracol. Por levar sua casa nas costas abordou-se o que havia na "casinha" da sala. As crianças disseram que não podiam fazer comida e nem lavar a louça porque não tinha fogão e pia. Assim, surgiu a idéia de

confeccionar estes objetos junto com o grupo. É possível visualizar o processo analisando as imagens abaixo. 

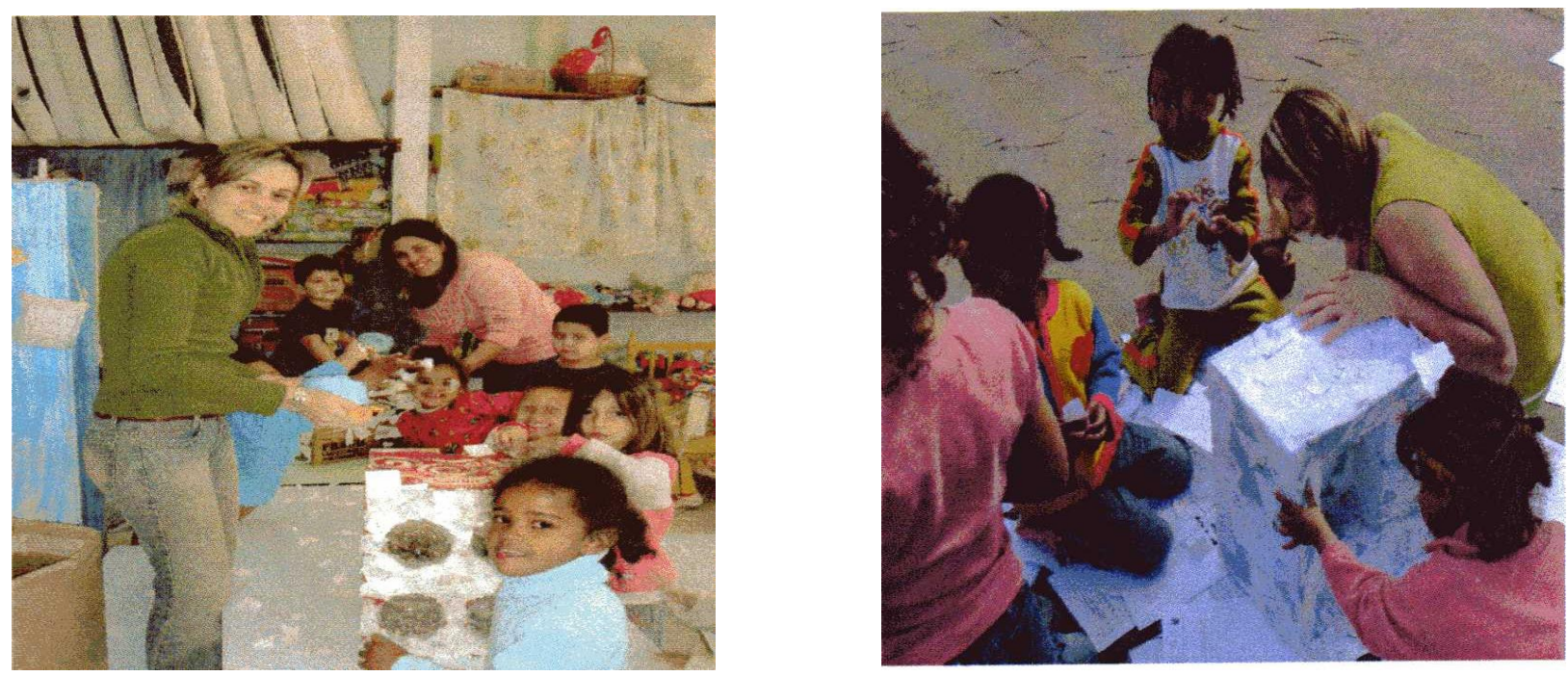

\section{Processo de papietagem.}
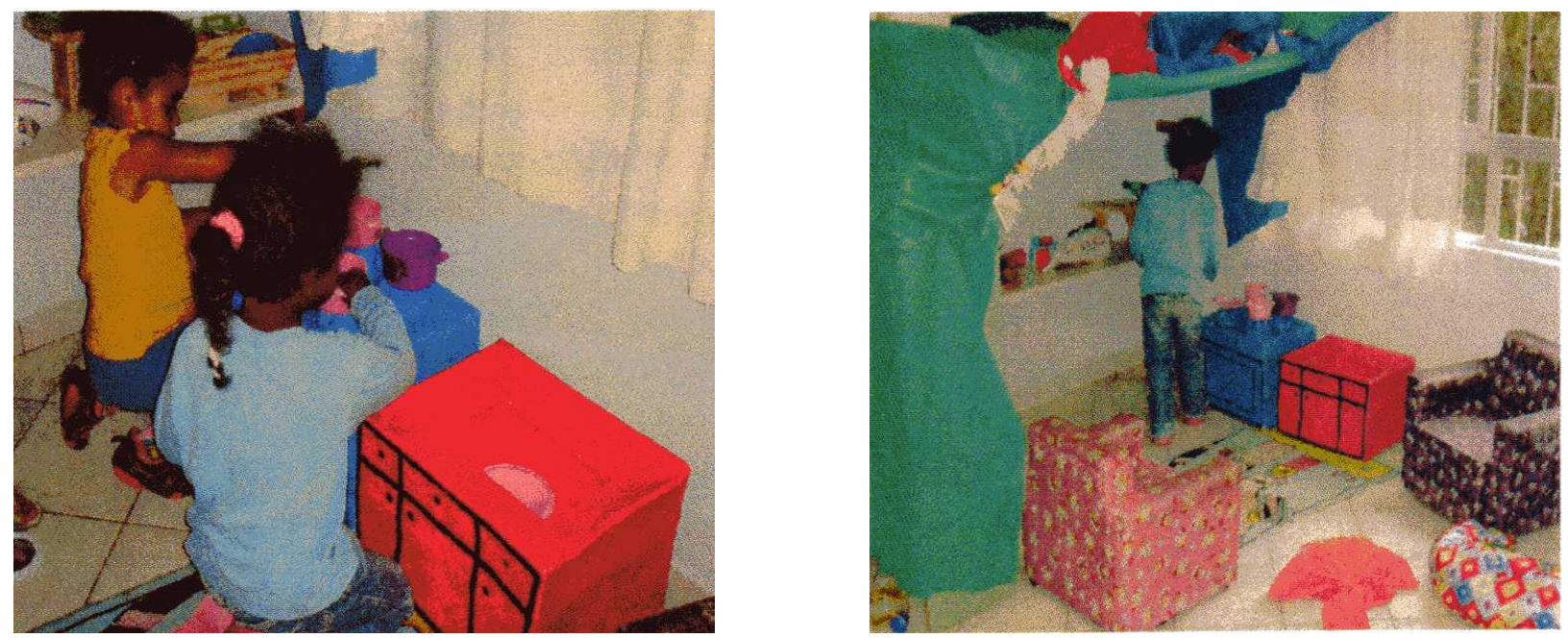

Objetos finalizados e inseridos na "casinha".

A linguagem é um sistema simbólico básico de todos os grupos humanos e a questão do desenvolvimento da linguagem e suas relações com o pensamento ocupa lugar de destaque, principalmente, na obra de Vygotsky. Segundo informa OLIVEIRA (1995), o pensador trabalha com duas funções básicas da linguagem. A principal função é a de intercâmbio social: é para se comunicar com seus semelhantes que o homem cria e utiliza os sistemas de linguagem.

É a necessidade de comunicação que impulsiona, inicialmente, o desenvolvimento da linguagem. Para que a comunicação com outros indivíduos seja possível de forma mais sofisticada, é necessário que sejam utilizados signos, compreensíveis por outras pessoas, que traduzam idéias, sentimentos, vontades, pensamentos, de forma bastante precisa. (OLIVEIRA apud Vygotsky, 1995, p. 42). 
Como cada indivíduo vive sua experiência pessoal de modo particular, suas experiências precisam ser simplificadas e generalizadas para poder ser traduzida em signos que possam ser transmitidos a outros. Ainda de acordo com Vygotsky, esse fenômeno gera uma segunda função da linguagem: a de pensamento generalizante. É essa função de pensamento generalizante que toma a linguagem um instrumento do pensamento.

Assim sendo, o ponto de partida para Vygotsky é investigar o tipo de relação que existe entre pensamento e linguagem e como essa relação vai se modificando à medida que a criança se aproxima da idade adulta. Em suma., busca explicar as transformações dinâmicas que essa relação vai adquirindo nas diferentes fases da vida da criança. $O$ pensamento e a linguagem têm origens diferentes e desenvolvem-se segundo trajetórias diferentes e independentes, antes que ocorra a estreita ligação entre esses dois fenômenos.

Com base na abordagem genética do desenvolvimento da linguagem, Vygotsky observa que o pensamento na criança pequena inicialmente evolui sem a linguagem; igualmente, os primeiros balbucios da criança se constituem numa forma de comunicação sem pensamento. Destaca, entretanto, que a função social da fala já é aparente desde os primeiros meses de vida da criança, ou seja, na fase pré-intelectual da linguagem. A criança tenta atrair, por meio de sons variados, a atenção do adulto, e comunica suas sensações de prazer e desprazer, que são habilmente decodificadas pela mãe ou adulto significativo do seu meio circundante. Portanto a criança, nos primeiros meses de vida, possui um pensamento pré-lingüístico e uma linguagem pré-intelectual. O momento crucial ocorre por volta dos dois anos, quando as curvas do pensamento pré-lingüístico e da linguagem pré- intelectual se encontram e se juntam, iniciando um novo tipo de organização do pensamento e da linguagem. Nesse momento o pensamento torna-se verbal e a fala, racional. A criança descobre, ainda que difusamente, que cada coisa tem seu nome e a fala começa a servir ao intelecto e os pensamentos começam a ser verbalizados. (SOUZA, 2001, p. 128).

Neste sentido, a criança primeiramente utiliza a fala socializada, com a função de comunicar, de manter um contato social. Com o desenvolvimento é que ela passa a ser capaz de utilizar a linguagem como instrumento de pensamento, com a função de adaptação pessoal, isto é, a apropriação do discurso é um processo gradual, que se completará em fases mais avançadas de aquisição da linguagem. A interação com membros mais maduros da cultura, que já dispõem de uma linguagem estruturada, é que vai provocar o salto qualitativo para o pensamento verbal. É deste modo, que a criança recria a linguagem verbal oral falada à sua volta como forma de participação da sociedade. A linguagem é recriada por meio dessa mesma participação — os outros, isto é, os seus interlocutores, têm um papel muito importante no processo da criança, mas quem refaz a linguagem é a criança. É o seu trabalho, agindo com a linguagem e sobre a linguagem, que os toma seres falantes e participantes no universo social.

Tivemos a oportunidade de exercer este papel de interlocutores em diversas atividades propostas no grupo de atuação do estágio, podemos exemplificar citando a dinâmica acerca do 
símbolo de uma das crianças (Roberta), sendo o seu símbolo a Cobra. Nesta atividade mostramos figuras de várias cobras, de diversas cores e tamanhos, e logo as crianças disseram que era o símbolo da Roberta. Perguntamos quem conhecia uma cobra e como era esta cobra? A maioria das crianças respondeu que já conheciam a cobra, falaram que era bem grande e que era vermelha a cor delas. Com uma fita indicamos os tamanhos de cobras que existe. Percebemos no decorrer da atividade que as crianças ficaram atentas, com expectativas e muito curiosas com o assunto abordado. Ao final das atividades com este símbolo, confeccionamos de tecido uma cobra gigante para ser utilizada como almofada nos momentos da roda, tornando-se a mesma a grande atração da sala durante o nosso período de coordenação.
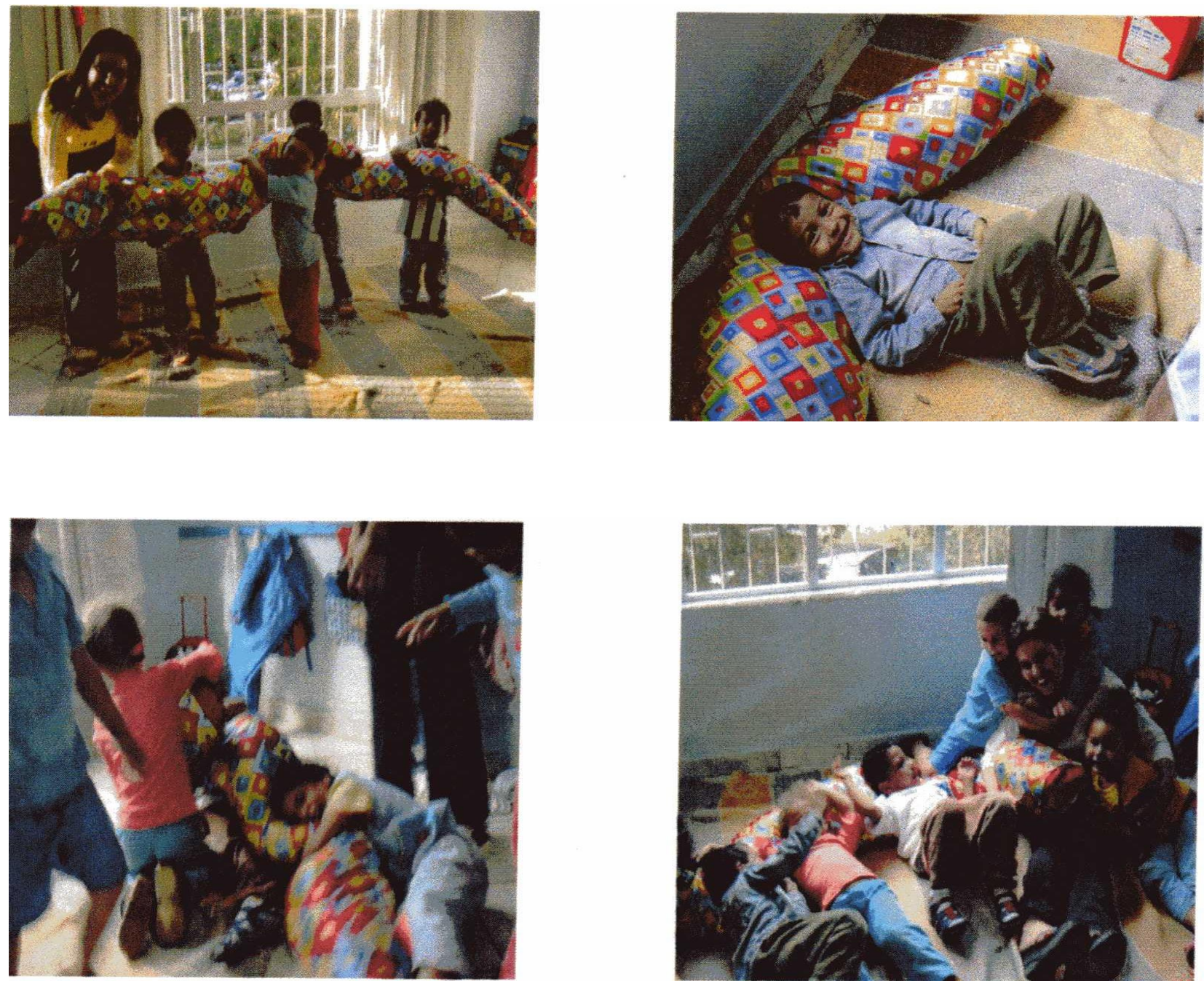

Conhecemos a cobra, descobrimos que elas são muitas e variadas, grandes e pequenas...

Outro momento marcante das nossas coordenações foi ao trabalhar o Coelho, símbolo de outra criança (Renato). Levamos um coelho e no pátio da creche todos puderam ver, tocar e alimentar o bicho. 

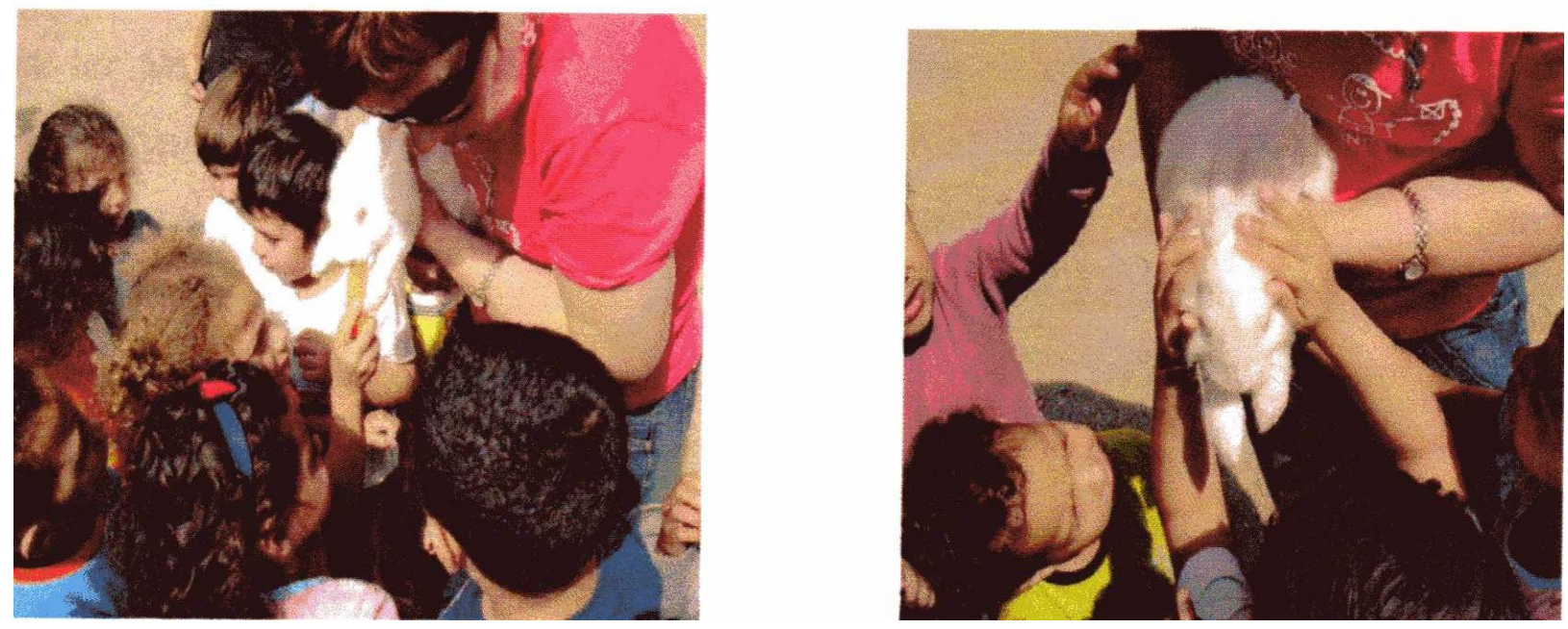

No momento seguinte, já na sala do grupo, em roda, as crianças tiveram um contato mais próximo com o coelho.
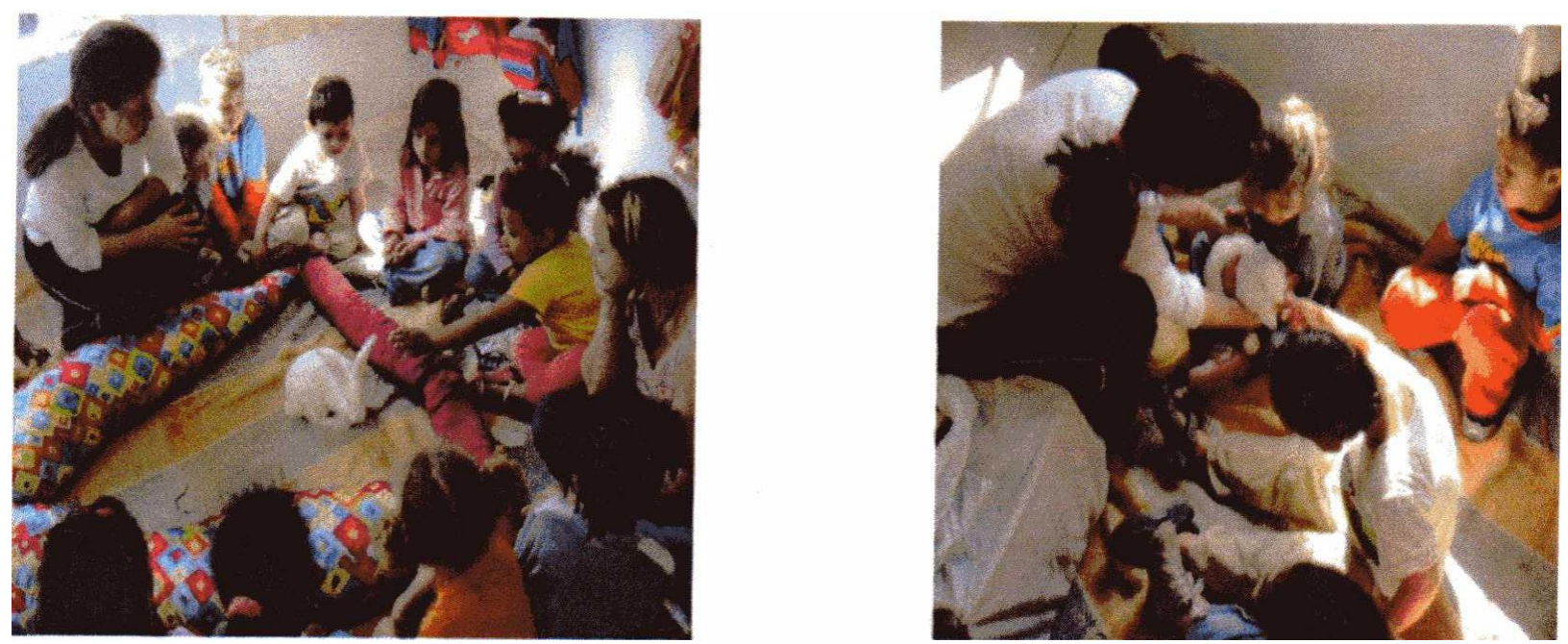

Foi um dia de grande entusiasmo e que por muitos dias ainda, as crianças ficaram comentando sobre o coelho...

Mediando essas experiências criamos muitas situações com materiais e brinquedos variados, possibilitando as crianças múltiplas formas de expressão. Ao criar essas inúmeras situações e vivências, fomos movidas pela preocupação em compreender melhor a relação entre linguagem escrita e as práticas educativas com crianças pequenas. 


\section{A Criança Pequena e a Linguagem Escrita}

O eixo deste item será acerca da reflexão sobre as formas de atuar na sociedade de cultura escrita. A questão em foco neste instante é a relação entre educação infantil e a linguagem escrita. A essência não está em como ensinar as crianças da educação infantil a ler e a escrever, mas sim em buscar uma ação pedagógica onde a multiplicidade de linguagens possa ter seu lugar reconhecido. Pertencer à cultura escrita é muito mais que saber ler e escrever. Aprender a ler e a escrever tem sido um ritual de iniciação em uma sociedade que se diz moderna e que se consolidou como escriturística. Está associada a uma certa alfabetização, normalmente entendida como aquisição da escrita enquanto habilidade motora e cognitiva e existindo como prática escolar geralmente imposta segundo um modelo único, ideal, controlado e decodificado.

O conceito de letramento trouxe para debate, na área da educação, uma série de novos questionamentos sobre as formas de apropriação da escrita. Esse processo coincide com desenvolvimento dos estudos sobre a escrita - compreendida como algo mais que cópia infiel da fala - isto é, sobre os discursos, os gêneros, os modos de ler e escrever e de aprender a ler e escrever, as formas de produzir textos e objetos de leitura.

As crianças observam palavras escritas em diferentes suportes antes mesmo de ingressar no espaço educacional, tais como placas, outdoors, rótulos de embalagens; escutam histórias lidas por outras pessoas, etc. Nessas experiências culturais com práticas de leitura e escrita, muitas vezes mediadas pela oralidade, as crianças se constituem como sujeitos letrados.

Pode-se dizer, de acordo com Britto (2003), que há quatro diferentes termos-conceito em uso atualmente: letramento, alfabetismo, alfabetização e cultura escrita. Letramento é certamente a palavra mais usada em tempos recentes, podendo receber várias interpretações. Um primeiro entendimento seria a distinção do processo de distribuição dos saberes, isto é, das ações políticosociais e pedagógicas de formação dos sujeitos na cultura escrita e suas habilidades de ler e escrever.

A segunda concepção, que se associa à idéia de alfabetizado, letrado ou educado, supõe aquilo que uma pessoa é capaz de fazer com seus conhecimentos de escrita, em diferentes esferas sociais. Outra interpretação diferencia a dimensão individual e a dimensão coletiva, isto é, entre capacidades individuais e comportamentos ou condições sociais. Quando se fala em letramento de um grupo, fala-se das formas de organização, intercâmbio, produção e circulação de produtos de cultura, bem como o estabelecimento de valores e padrões de comportamento. 
Já o termo alfabetização, mais popular e tradicional de todos, sofreu profunda ressignificação nos anos de 1970 e 1980, quando deixa de ser considerado apenas o processo de ensino e aprendizagem do sistema de escrita, com seus modelos e regras. A inclusão do conceito de letramento na educação tem provocado a retomada da idéia de alfabetização como simples aquisição do sistema de códigos, como se alguém pudesse aprender a ler e a escrever sem aprender simultaneamente objetos culturais e comportamentos cognitivos associados a essa aprendizagem.

Alfabetismo é outro termo que guarda relação direta com alfabetização ou alfabetizar (processo) e alfabetizado ou analfabeto (condição individual). É a apreensão da noção de habilidades estritamente relacionadas ao uso da escrita em suas várias esferas.

Cultura escrita procura caracterizar um modo de organização social cuja base é a escrita algo que não se modificou em essência mesmo com o advento das novas tecnologias. Sendo mais abrangente, esse termo poderia abarcar não apenas os outros três como subcomponentes de um campo mais amplo, como explicitaria um modo de produção social. Cultura escrita implica valores, conhecimentos, modos de comportamento que não se limitam ao uso objetivo da escrita.

Aí está um desafio difícil: inserir a criança no mundo da escrita é mais que alfabetizá-la, se entendermos por alfabetização apenas o domínio do código; ou é iniciar a alfabetização, se compreendermos por alfabetização a inclusão em um universo cultural complexo em que a escrita aparece como mediadora de valores e de formas de conhecimento. Letramento (ou alfabetização), deste modo, significa viver no mundo da escrita, dominar os discursos da escrita, ter condições de operar com os modos de pensar e produzir da cultura escrita.

Não há nada de errado em alfabetizar as crianças. É justo que elas sejam alfabetizadas, porém que seja dentro de propostas pedagógicas consistentes e organizadas. Mas é preciso ter claro que alfabetizar não é formar no domínio de uma técnica e, sim, pôr a pessoa no mundo da escrita de modo que ela tenha condições de operar criticamente com os modos de pensar e produzir da cultura escrita. Propor atividades de expressão, tais como: desenho, pintura, brincadeira de faz-de-conta, modelagem, construção, dança, poesia e a própria fala, são essenciais para a formação da identidade, da inteligência e da personalidade da criança, além de constituírem as bases para a aquisição da escrita como um instrumento cultural complexo. 


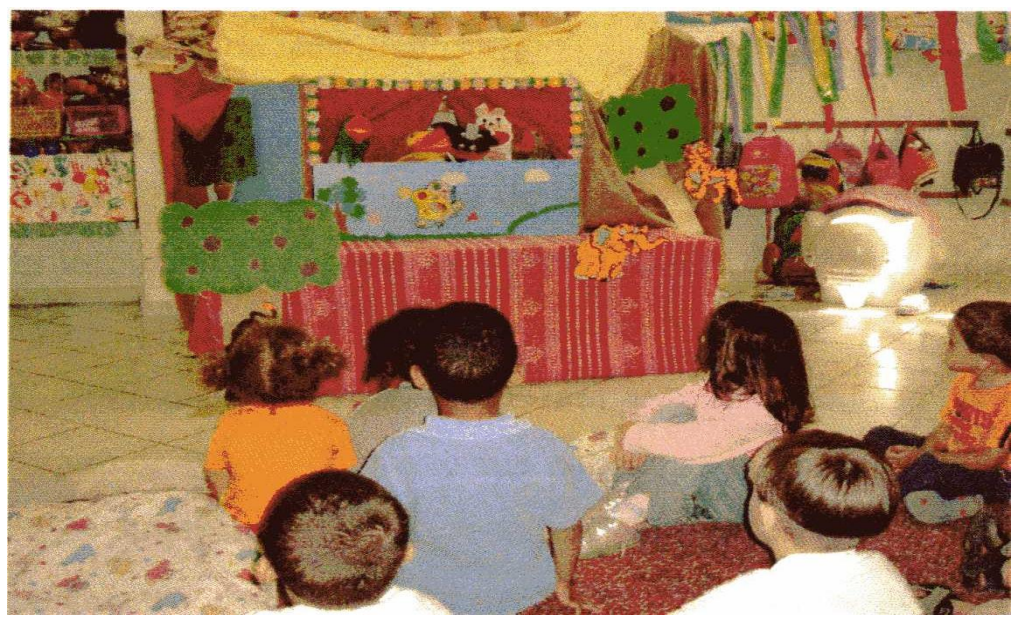

Teatro com fantoches, realizado pelas estagiárias dos grupos G4C e G5A.

No espaço educacional, é possível aprender novos modos de falar, de ler a realidade, de conhecer outras formas de viver, falar e se comportar; permitem-se outras expressões, as artes ligadas ao movimento e ao ritmo, como a dança e a música. São diferentes modos de ler, mostrar e falar da realidade.
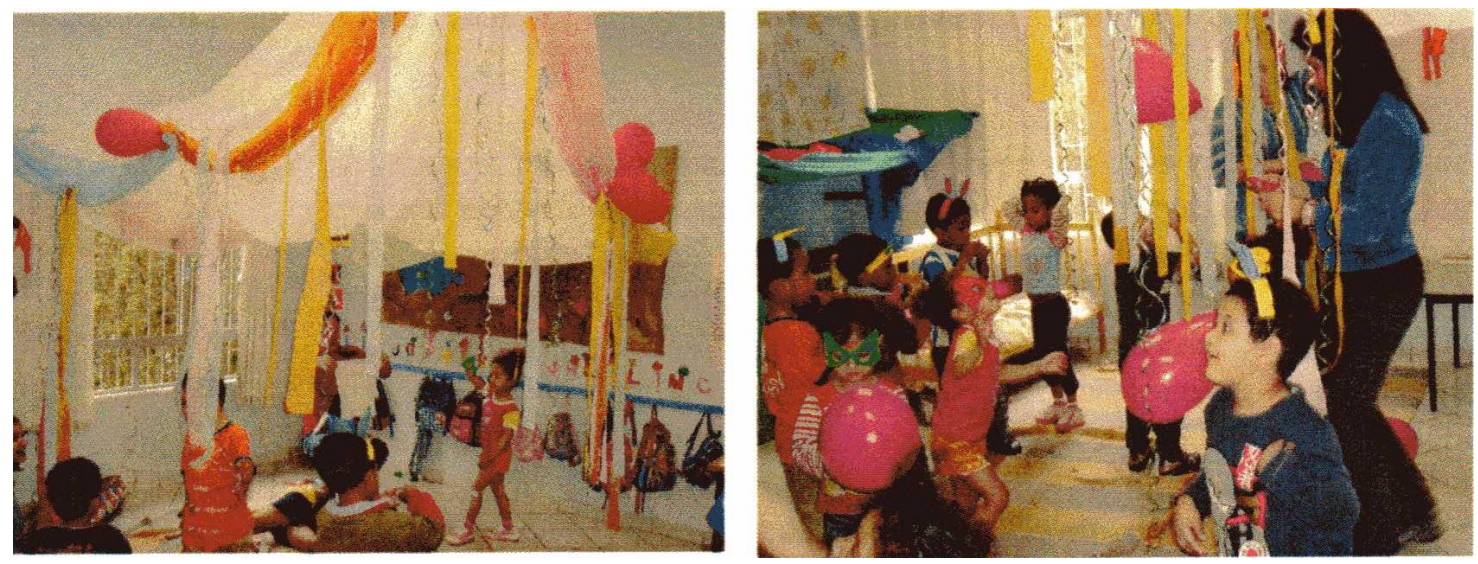

[...] colocou-se música e na tenda dos bichos, que estava bem colorida e enfeitada, as crianças dançaram e brincaram com balões. As crianças do grupo G4C também participaram da festa, pois as estagiárias dos dois grupos organizaram juntas a festa de encerramento, intitulando-a de "Festa dos Bichos". A festa começou, as crianças do outro grupo chegaram e a alegria tomou conta de todos. (REGISTRO, 24/10/2007).

Na década de 1920, Vygotsky já dizia que "Ensinamos às crianças a traçar as letras e a formar palavras com elas, mas não ensinamos a linguagem escrita” (MELLO apud Vygotsky, 2005, p. 26). Para Mello, o teórico queria dizer com isso que:

“[...] na forma como em geral apresentamos a escrita para a criança, o ensino do mecanismo prevalece sobre a utilização racional, funcional e social da escrita. Criticava o fato de que em seu tempo, e também ainda hoje, de maneira geral, o ensino da escrita se baseia em um conjunto de procedimentos artificiais...” (2005, p. 26). 
A escrita "se forma por um sistema de signos que identificam convencionalmente os sons e palavras da linguagem oral que são, por sua vez, signos de objetos e relações reais" (MELLO apud Vygotsky, 2005, p. 26). Em outras palavras, a autora expõe que a escrita representa a fala, que, por sua vez, representa a realidade. Por isso, a escrita é uma representação de segunda ordem. Para que sua aquisição se dê de forma efetiva, no entanto, é preciso que o nexo intermediário - representado pela linguagem oral - desapareça gradualmente e a escrita se transforma em um sistema de signos que simbolizem diretamente os objetos e as situações indicadas. Somente assim, o leitor será capaz de ler idéias e não palavras compostas de sílabas num texto. Da mesma forma, ao escrever, registrará idéias e não apenas grafará palavras.

Para Luria (1988), a história da escrita na criança começa muito antes da primeira vez em que o professor coloca um lápis em sua mão e lhe mostra como formar letras. Pode-se dizer que quando uma criança entra na escola, ela já adquiriu um repertório de habilidades que a certificará a aprender a escrever em um tempo relativamente curto.

\begin{abstract}
Se apenas pararmos para pensar na surpreendente rapidez com que uma criança aprende esta técnica extremamente complexa, que tem milhares de anos de cultura por trás de si, ficará evidente que isso só pode acontecer porque durante os primeiros anos de seu desenvolvimento, antes de atingir a idade escolar, a criança já aprendeu e assimilou um certo número de técnicas que prepara o caminho para a escrita, técnicas que a capacitam e que tornaram incomensuravelmente mais fácil aprender o conceito e a técnica da escrita. Além disso, podemos razoavelmente presumir que mesmo antes de atingir a idade escolar, durante por assim dizer, esta "pré-história" individual, a criança já tinha desenvolvido, por si mesma, um certo número de técnicas primitivas, semelhantes aquilo que chamamos escrita e capazes de, até mesmo, desempenhar funções semelhantes, mas que são perdidas assim que a escola proporciona a criança um sistema de signos padronizados e econômico, culturalmente elaborado. (LURIA, 1988, p. 143-144).
\end{abstract}

Vygotsky, conforme Meilo (2005), já apresenta a aquisição da escrita como resultado de um longo processo de desenvolvimento das funções mentais superiores do comportamento infantil, que o pensador chama de pré-história da linguagem escrita. Começa com a escrita no ar, com o gesto da criança ao qual nós, adultos, atribuímos um significado. Entre o gesto e o código escrito dois elementos se intercalam: o desenho e o faz-de-conta.

Ao observar, percebe-se que o desenho, como um seguimento do gesto, inicialmente é uma representação do gesto. Aos poucos, ele torna-se uma representação simbólica e gráfica do objeto. Da mesma forma, no faz-de-conta, a falta de alguns objetos necessários à brincadeira é compensada por objetos que passam a representar os ausentes e, aos poucos, se convertem em signos que representam estes objetos ausentes.

Deste modo, a criança vai tomando mais elaborado o modo como utiliza as diversas formas de representação, entendendo-se que a representação simbólica no faz-de-conta e no desenho é uma etapa anterior e uma forma de linguagem que leva à linguagem escrita. 

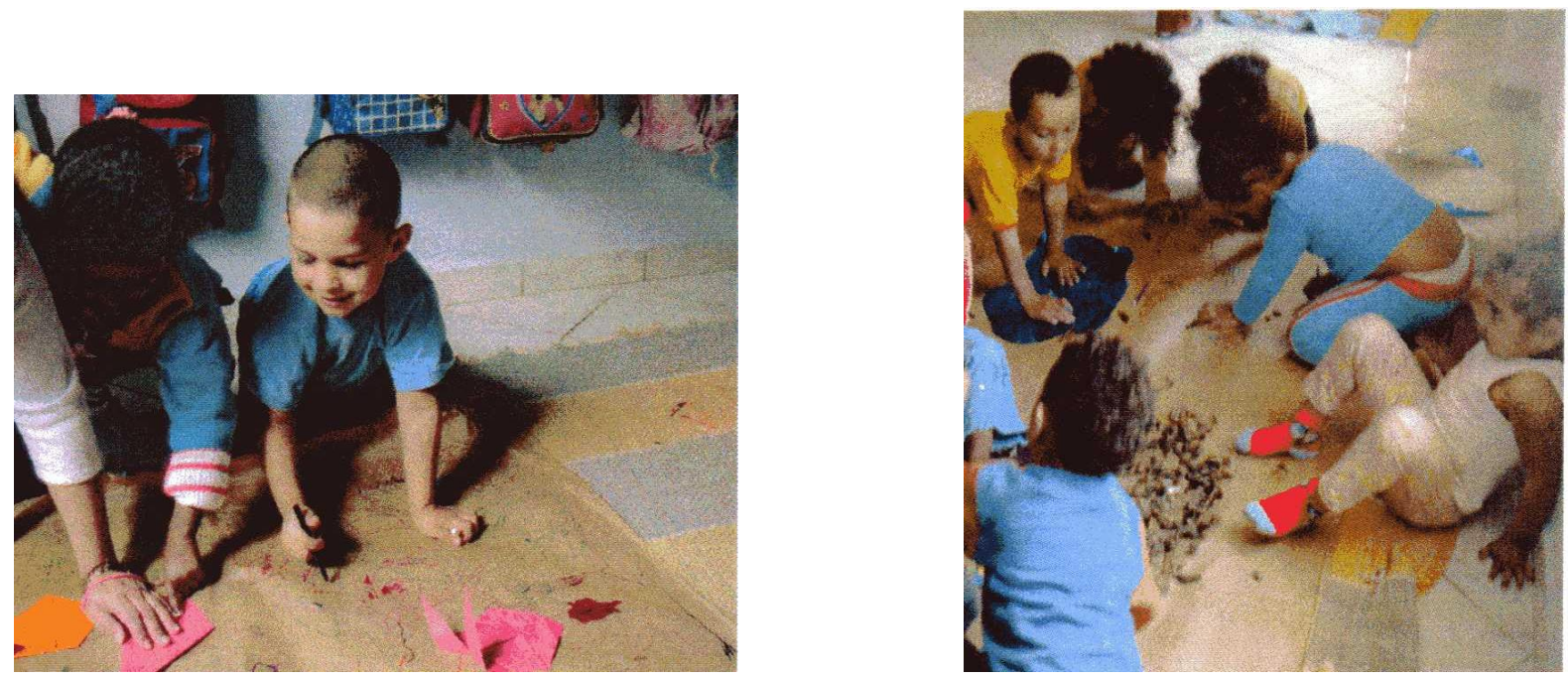

[...] distribuímos para as crianças canetinhas coloridas para desenharem alguns bichos no painel. Algumas crianças desenharam flores, outras desenharam peixinhos no lago. Eles ficaram muito eufóricos, querendo desenhar em todos os espaços do papel, rabiscaram bastante e deixaram bem colorido o painel com o caminho dos bichos. (REGISTRO, 17/10/2007).

Por isso, ao querer que as crianças se apropriem efetivamente da escrita - não de forma mecânica, mas como uma linguagem de expressão e de conhecimento do mundo - precisa-se garantir que se utilizem profundamente do faz-de-conta e do desenho livre, vividos como forma de expressão e de atribuição pessoal de significado àquilo que a criança vai conhecendo no mundo da cultura.

\begin{abstract}
Os educadores devem organizar todas essas ações e todo o complexo processo de transição de um tipo de linguagem escrita para outro. Devem acompanhar este processo através de seus momentos críticos, até o ponto da descoberta de que se pode desenhar não somente objetos, mas também a fala. Se quiséssemos resumir todas essas demandas práticas e expressá-las de uma forma unificada, poderíamos dizer que o que se deve fazer é ensinar as crianças a linguagem escrita e não apenas a escrita de letras (OLIVEIRA apud Vygotsky, 1995, p. 72).
\end{abstract}

Antecipar o ensino das letras, em vez de trazer o debate da cultura escrita no cotidiano, é inverter o processo e aumentar a diferença. As crianças e os adultos escrevem e lêem não só com as letras. E não basta antecipar para garantir o direito e o prazer de ler e de escrever mais tarde.

Foi possível perceber durante o período de estágio do curso de Educação Infantil, bem como das leituras realizadas para a elaboração deste relatório final, que nossa prática educativa deve permitir as vivências do universo cultural e as diversas expressões das linguagens, além de ampliar as experiências das crianças. Também compreendemos que a Educação Infantil não é o momento de ensinar a desenhar e juntar as letras, e sim o de oferecer condições para que as crianças sejam efetivos participantes do mundo da cultura escrita.

Consideramos que o profissional da educação infantil deve proporcionar uma organização do tempo e do espaço diferente do mundo adulto, organizando-o para que as crianças produzam as 
culturas infantis, para que as crianças sejam crianças. O mais importante ainda é a necessidade que sentimos de nos alfabetizar nessas diversas linguagens sem letra e sem escrita.

\section{REFERÊNCIAS BIBLIOGRÁFICAS}

BLUMENAU, SECRETARIA MUNICIPAL DE EDUCAÇÃO. Cadernos da Educação Infantil (Retratos da Rede: Organização, Tempos, Espaços, Fazeres.) nº 01. Blumenau, 2002.

BRASIL. Referencial Curricular Nacional para Educação Infantil. Brasília: MEC/SEF, 1998.

BRITTO, Luiz Percival Leme. Letramento e Alfabetização - Implicações para a Educação Infantil. In: FARIA, Ana Lúcia Goulart de; MELLO, Suely Amaral (orgs.). O Mundo da Escrita no Universo da Pequena Infância. Campinas, SP: Autores Associados, 2003. (Coleção polêmicas do nosso tempo). LURIA, Aleksander Romanovich. O Desenvolvimento da Escrita na Criança. In: VIGOTSKY, Lev Semenovich; LURIA, Aleksander Romanovich; LEONT'EV, A!eksei Mikoiaievich. Linguagem, desenvolvimento e aprendizagem. São Paulo: EDUSP, 1988.

MELLO, Suely Amaral. O Processo de Aquisição da Escrita na Educação Infantil — Contribuições de Vygotsky. In: FARIA, Ana Lúcia Gou!art de; MELLO, Suely Amaral (orgs.). Linguagens Infantis - Outras formas de leitura. Campinas, SP: Autores Associados, 2005. (Coleção polêmicas do nosso tempo).

OLIVEIRA, Marta Kohl de. Vygotsky: aprendizado e desenvolvimento um processo sócio- histórico. 2. ed. São Paulo: Scipione, 1995.

SOUZA, Solange Jobim e. Infância e Linguagem: Bakhtin, Vygotsky e Benjamin. 6. ed. Campinas, SP: Papirus, 2001.

VIGOTSKY, Lev Semenovich; COLE, Michael et ai (orgs.). A Formação Social da Mente: o desenvolvimento dos processos psicológicos superiores. 6. ed. São Paulo: Martins Fontes, 1998.

VIGOTSKY, Lev Semenovich. Pensamento e Linguagem. 3. ed. São Paulo: Marfins Fontes, 1991. 